\title{
Solving Some Oscillatory Problems using Adomian Decomposition Method and Haar Wavelet Method
}

\author{
I. Haq", I. Singh \\ Department of Mathematics, Sant Baba Bhag Singh University, Jalandhar-144030, Punjab, India
}

Received 27 November 2019, accepted in final revised form 27 January 2020

\begin{abstract}
In this research, we presented two classical numerical techniques to solve some oscillatory problems arised in various applications of sciences and engineering. Adomian decomposition method (ADM) and Haar wavelet method (HWM) are utilized for this purpose. Some numerical examples have been performed to illustrate the accuracy of the present methods.
\end{abstract}

Keywords: Adomian Decomposition method; Haar wavelet method; Operational matrices; Numerical examples.

(C) 2020 JSR Publications. ISSN: 2070-0237 (Print); 2070-0245 (Online). All rights reserved.

doi: http://dx.doi.org/10.3329/jsr.v12i3.44287 J. Sci. Res. 12 (3), 289-302 (2020)

\section{Introduction}

One of the most difficult problem in numerical solutions of the ordinary differential equations is the development of numerical methods which are dealing with oscillatory solutions. Classical numerical methods require a huge number of time steps to track the oscillations and with the small step size, they can alter the dynamics. Many numerical methods have been developed for solving these second order differential equations such as Runge-Kutta method, Finite difference method (FDM) and Finite element method (FEM). A new explicit Runge-Kutta method of fifth algebraic order has been developed by Hussain et al. for solving second-order ordinary differential equations with oscillatory solutions [1]. A set of order condition for block explicit hybrid method up to order five has been presented for the approximation of special second order delay differential equations with oscillatory solutions [2]. Runge-Kutta methods have been adapted to the numerical integration of oscillatory problems [3]. Finite element method based Galerkin weighted residual technique is used for solving natural convection flow in a hexagonal enclosure with a single vertical fin attached to its heated bottom wall [4]. The mixed convection in square lid-driven with internal elliptic body and constant flux heat source on the bottom wall has been numerically simulated by Munshi et al. with finite element method [5]. The Adomian Decomposition method (ADM) was firstly introduced by

\footnotetext{
* Corresponding author: shahirfan3926@gmail.com
} 
Adomian [6] in 1981. This method has been applied for solving linear and nonlinear differential and integral equations arising in mathematics, physics, biology and chemistry and up to now large number of research papers have been published to show the feasibility of the decomposition method. The main advantage of this method is that it can be applied directly to all types of differential and integral equations which are homogeneous or non-homogeneous, with constant or variable coefficients. Another important advantage of this method is that it greatly reduces the size of computation work while still maintaining high accuracy of the numerical solution as discussed by Somali and Gokmen [7]. The ADM decomposes a solution into an infinite series which converges rapidly to the exact solution. The convergence of the ADM has been investigated by Cherruault [8] and Mustafa [9]. Wavelet transform and wavelet analysis are recently developed mathematical tools for solving differential and integral equations. Chen and Hsiao [10] gave a method for solving linear systems of ordinary differential equations and partial differential equations based on Haar wavelet. Haar wavelet is the simplest orthonormal wavelet with compact support and has been utilized for solving linear as well as non-linear differential and integral equations. Haar wavelet method has been used for solving ordinary and partial differential equations [11-18]. Since solutions of ordinary and partial differential equations which are not enough smooth, when approximated by cubic, quadratic and linear polynomials results in poor convergence or no convergence in results and in such cases, an approximation of zero degree polynomials like Haar wavelets (continuous functions with finite jumps) are more suitable and successful. The main advantages of the Haar wavelet method is its simplicity and small computation costs: it is due to the sparcity of the transform matrices and to the small number of significant wavelet coefficients. In this research paper, we are presenting two classical numerical techniques to find the solutions of oscillatory problems arising in science and engineering and discussed different cases that have arised during oscillatory process.

\section{Adomian Decomposition Method}

Consider differential equation

$\mathrm{Ly}+\mathrm{Ry}+\mathrm{Ny}=\mathrm{g}(\mathrm{x})$

Where $N$ is a non-linear operator, $L$ is the highest order derivative which is assumed to be invertible and $R$ is a linear differential operator of order less than $L$. Making $L y$ subject to formula, we obtain

$\mathrm{Ly}=\mathrm{g}(\mathrm{x})-\mathrm{Ry}-\mathrm{Ny}$

By solving (2) for $L y$, since $L$ is invertible, we can write

$\mathrm{L}^{-1} \mathrm{Ly}=\mathrm{L}^{-1} \mathrm{~g}(\mathrm{x})-\mathrm{L}^{-1} \mathrm{Ry}-\mathrm{L}^{-1} \mathrm{Ny}$

For initial value problems we define $L^{-1}$ for $L=\frac{d^{n}}{d x^{n}}$ as the definite integration from 0 to x. If $L$ is second-order operator, $L^{-1}$ is integral and by solving (3) for $y$, we obtain

$\mathrm{y}=\mathrm{A}+\mathrm{Bx}+\mathrm{L}^{-1} \mathrm{~g}(\mathrm{x})-\mathrm{L}^{-1} \mathrm{Ry}-\mathrm{L}^{-1} \mathrm{Ny}$

where $A$ and $B$ are constants of integration and can be found from the initial or boundary conditions. The Adomian method consists of approximating the solution of (1) as an infinite series.

$\mathrm{y}(\mathrm{x})=\sum_{\mathrm{n}=0}^{\infty} \mathrm{y}_{\mathrm{n}}(\mathrm{x})$

and decomposing the non-linear operator $N$ as

$N(y)=\sum_{n=0}^{\infty} A_{n}$

where $A_{n}$ are Adomian polynomials $[19,20]$ of $y_{0}, y_{1}, y_{2}, \ldots, y_{n}$ given by 
$\mathrm{A}_{\mathrm{n}}=\frac{1}{\mathrm{n} !} \frac{\mathrm{d}^{\mathrm{n}}}{\mathrm{d} \lambda^{\mathrm{n}}}\left[\mathrm{N}\left(\sum_{\mathrm{i}=0}^{\infty} \lambda^{\mathrm{i}} \mathrm{y}_{\mathrm{i}}\right)\right]_{\lambda=0}, \mathrm{n}=0,1,2, \ldots$

Substituting (5) and (6) into (4) we get

$\sum_{n=0}^{\infty} y_{n}=A+B x+L^{-1} g(x)-L^{-1} R\left(\sum_{n=0}^{\infty} y_{n}\right)-L^{-1}\left(\sum_{n=0}^{\infty} A_{n}\right)$.

The recursive relationship is found to be

$\mathrm{y}=\mathrm{g}(\mathrm{x})$

$y_{n+1}=-L^{-1} R y_{n}-L^{-1} A_{n}$

Using the above recursive relationship, we can make solution of $y$ as

$y=\lim _{n \rightarrow \infty} \Phi_{n}(y)$,

where

$\Phi_{\mathrm{n}}(\mathrm{y})=\sum_{\mathrm{i}=0}^{\mathrm{n}} \mathrm{y}_{\mathrm{i}}$

\section{Convergence Analysis of ADM}

Consider the equations $y^{\prime \prime}(t)=f(t, y)$ with $y(0)=y_{0}, y^{\prime}(0)=y_{1}$. This equation can be written as:

$\mathrm{y}^{\prime \prime}=\mathrm{Ly}+\mathrm{N}(\mathrm{y}), \mathrm{t}>0, \quad y(0)=\mathrm{f}, \mathrm{y}^{\prime}(0)=\mathrm{f}^{\prime}$

where $L: T \rightarrow X$ is a linear operator of form a Banach space $T$ to a Banach space $X(T \subseteq$ $X), N(y): T \rightarrow T$ is a nonlinear function on the Banach space $T$ and $f, f^{-1} \in T$ are initial data. Consider the abstract functional equation defined by

$\mathrm{y}=\mathrm{y}_{0}+\mathrm{y}_{1}(\mathrm{t})+\mathrm{f}(\mathrm{y}), \mathrm{y} \in \mathrm{T}$

where $T$ is a Banach space and $f(y): T \rightarrow T$ is analytic near the initial conditions $y_{0}$ and $y_{1}$.

$$
\left.\begin{array}{c}
\mathrm{Y}_{\mathrm{n}}=\mathrm{y}_{0}+\mathrm{y}_{1}(\mathrm{t})+\sum_{\mathrm{k}=2}^{\mathrm{n}} \mathrm{y}_{\mathrm{k}} \\
\mathrm{f}\left(\mathrm{Y}_{\mathrm{n}}\right)=\sum_{\mathrm{k}=0}^{\mathrm{n}} \mathrm{A}_{\mathrm{k}}\left(\mathrm{y}_{0}, \mathrm{y}_{1}, \ldots, \mathrm{y}_{\mathrm{k}}\right.
\end{array}\right\}
$$

The ADM is equivalent to determining a sequence $\left\{Y_{n}\right\}_{n \in N}$ from

$$
\left.\begin{array}{c}
\mathrm{Y}_{0}=\mathrm{y}_{0}+\mathrm{y}_{1}(\mathrm{t}) \\
\mathrm{Y}_{\mathrm{n}+1}=\mathrm{y}_{0}+\mathrm{y}_{1}(\mathrm{t})+\mathrm{f}_{\mathrm{n}}(\mathrm{Y})_{\mathrm{n}}, \mathrm{n} \geq 0
\end{array}\right\}
$$

If the limits

$$
\left.\begin{array}{l}
Y=\lim _{n \rightarrow \infty} Y_{n} \\
f=\lim _{n \rightarrow \infty} f_{n}
\end{array}\right\}
$$

exist in Banach space $T$, then $Y$ solves the fixed point equation $Y=y_{0}+y_{1}(t)+f(y)$ in $T$. It is also assumed that the following condition holds

$$
\left.\begin{array}{c}
\|\mathrm{f}(\mathrm{y})\|_{\mathrm{T}} \leq 1, \forall \mathrm{y} \in \mathrm{T} \\
\text { and } \\
\left\|\mathrm{f}_{\mathrm{n}}\left(\mathrm{Y}_{\mathrm{n}}\right)-\mathrm{f}(\mathrm{y})\right\|_{\mathrm{r}} \rightarrow 0 \text { as } \mathrm{n} \rightarrow \infty
\end{array}\right\}
$$

These two conditions are rather restrictive. The first condition implies a constraint on the nonlinear function $f(y)$ and the second condition implies convergence of the series of Adomian polynomial to the locally analytic function $f(y)$. 


\section{Haar Wavelet Method}

Haar Wavelet family for $t \in[0,1]$ is defined as follows.

$$
h_{i}(t)=\left\{\begin{array}{c}
1, \quad \text { for } t \in\left[\frac{k}{m}, \frac{k+0.5}{m}\right) \\
-1, \text { for } t \in\left[\frac{k+0.5}{m}, \frac{k+1}{m}\right) \\
0, \text { elsewhere }
\end{array}\right.
$$

Integer $m=2^{j}((j=0,1,2 \ldots \ldots)$ indicates the level of the wavelet, $k=0,1,2, \ldots m-1$ is the translation parameter. Maximal level of resolution is $j$. The index $i$ is calculated according to the formula $i=m+k+1$; in the case of minimal value. $m=1, k=0$ we have $i=2$, the maximal value of $i$ is $i=2 M=2^{j+1}$. It is assumed that the value of $i=1$ corresponds to the scaling function for which $h_{1}=1$ in $[0,1]$. Let us define the collocation points $t_{1}=(l-0.5) / 2 M,(l=1,2, \ldots \ldots 2 M)$ and discretize the Haar function $h_{1}(t)$; in this way we get the coefficient matrix $H(i, l)=\left(h_{i}\left(t_{1}\right)\right)$, which has dimensions $2 M \times 2 M$. The operational matrix of integration $P$, which is a $2 M$ square matrix, is defined by the equation .

$$
\begin{aligned}
& (\mathrm{PH})_{\mathrm{a}}=\int_{0}^{\mathrm{t}_{1}} \mathrm{~h}_{\mathrm{i}}(\mathrm{t}) \mathrm{dt} \\
& (\mathrm{QH})_{\mathrm{a}}=\int_{0}^{\mathrm{t}_{1}} \mathrm{dt} \int_{0}^{\mathrm{t}} \mathrm{h}_{1}(\mathrm{t}) \mathrm{dt}
\end{aligned}
$$

The elements of matrix H, P and Q can be evaluated according to (9), (10) and (11).

$$
\begin{aligned}
& \mathrm{H}_{1}=\left[\begin{array}{cc}
1 & 1 \\
1 & -1
\end{array}\right] \\
& \mathrm{P}_{2}=\frac{1}{4}\left[\begin{array}{cc}
2 & -1 \\
1 & 0
\end{array}\right] \\
& \mathrm{H}_{4}=\left[\begin{array}{cccc}
1 & 1 & 1 & 1 \\
1 & 1 & -1 & -1 \\
1 & -1 & 0 & 0 \\
0 & 0 & 1 & -1
\end{array}\right] \\
& \mathrm{P}_{4}=\frac{1}{16}\left[\begin{array}{cccc}
8 & -4 & -2 & -2 \\
4 & 0 & -2 & 2 \\
1 & 1 & 0 & 0 \\
1 & -1 & 0 & 0
\end{array}\right] \\
& \mathrm{P}_{4}=\frac{1}{64}\left[\begin{array}{cccccccc}
32 & -16 & -8 & -8 & -4 & -4 & -4 & -4 \\
16 & 0 & -8 & 8 & -4 & -4 & 4 & 4 \\
4 & 4 & 0 & 0 & -4 & 4 & 0 & 0 \\
4 & 4 & 0 & 0 & -4 & 4 & 0 & 0 \\
1 & 1 & 2 & 0 & 0 & 0 & 0 & 0 \\
1 & 1 & -2 & 0 & 0 & 0 & 0 & 0 \\
1 & -1 & 0 & 2 & 0 & 0 & 0 & 0 \\
1 & -1 & 0 & -2 & 0 & 0 & 0 & 0
\end{array}\right]
\end{aligned}
$$

Chen and Hsiao [10] showed the following matrix equation for calculating the matrix $P$ of the order $m$ holds.

$\mathrm{P}_{(\mathrm{m})}=\frac{1}{2 \mathrm{~m}}\left(\begin{array}{cc}2 \mathrm{mP}_{(\mathrm{m} / 2)} & -\mathrm{H}_{(\mathrm{m} / 2)} \\ \mathrm{H}^{-1}{ }_{(\mathrm{m} / 2)} & 0\end{array}\right)$

where $O$ is a null matrix of order $\frac{m}{2} \times \frac{m}{2}$

$\mathrm{H}_{\mathrm{mXm}} \triangleq\left[\mathrm{h}_{\mathrm{m}}\left(\mathrm{t}_{0}\right) \mathrm{h}_{\mathrm{m}}\left(\mathrm{t}_{1}\right) \ldots \ldots \ldots \ldots \mathrm{h}_{\mathrm{m}}\left(\mathrm{t}_{\mathrm{m}-1}\right)\right]$

and $\frac{\mathrm{i}}{\mathrm{m}} \leq \mathrm{t}<i+\frac{1}{\mathrm{~m}}$ and $\mathrm{H}_{\mathrm{mxm}}^{-1}=\frac{1}{\mathrm{~m}} \mathrm{H}_{\mathrm{mxm}}^{\mathrm{T}} \operatorname{diag}(\mathrm{r})$. 
It should be noted that calculations for $P_{(m)}$ and $H_{(m)}$ must be carried out only once. After that they will be applicable for solving whatever differential equations. Since $H$ and $H^{-1}$ contains many zeros, this phenomenon makes the Haar transform must faster than the Fourier transform, and it is even faster than walsh transform. This is one of the reason for rapid convergence of the Haar wavelet series.

\section{Function Approximation}

Any function $y(x) \in L^{2}[0,1)$ can be decomposed as

$\mathrm{y}(\mathrm{x})=\sum_{\mathrm{n}=0}^{\infty} \mathrm{c}_{\mathrm{n}} \mathrm{h}_{\mathrm{n}}(\mathrm{x})$

where the coefficients $c_{n}$ are determined by

$\mathrm{c}_{\mathrm{n}}=2^{\mathrm{j}} \int_{0}^{1} \mathrm{y}(\mathrm{x}) \mathrm{h}_{\mathrm{n}}(\mathrm{x}) \mathrm{dx}$

where $\mathrm{n}=2^{\mathrm{j}}+\mathrm{k}, \mathrm{j} \geq 0,0 \leq \mathrm{k}<2^{\mathrm{j}}$. specially $\mathrm{c}_{0}=\int_{0}^{1} \mathrm{y}(\mathrm{x}) \mathrm{dx}$.

The series expansion of $y(x)$ contains an infinite terms. If $y(x)$ is piecewise constant by itself, or may be approximated as piecewise constant during each subinterval, then $y(x)$ will be terminated as finite terms, that is:

$\mathrm{y}(\mathrm{x})=\sum_{\mathrm{n}=0}^{\mathrm{m}-1} \mathrm{c}_{\mathrm{n}} \mathrm{h}_{\mathrm{n}}(\mathrm{x})=\mathrm{c}^{\mathrm{t}}(\mathrm{m}) \mathrm{h}_{(\mathrm{m})}(\mathrm{x})$

where the coefficients $c^{T}{ }_{(m)}$ and the Haar function vector $h_{(m)}(x)$ are defined as follow:

$\mathrm{c}^{\mathrm{T}}(\mathrm{m})=\left[\mathrm{c}_{0}, \mathrm{c}_{1}, \ldots \ldots \ldots \ldots, \mathrm{c}_{\mathrm{m}-1}\right]$

and $h_{(m)}(x)=\left[h_{(0)}(x),\left[h_{0}(x), h_{1}(x), \ldots \ldots \ldots, h_{m-1}(x)\right]\right]^{T}$, where $T$ means transpose and $m=2^{j}$.

\section{Numerical Observations}

In this section, we have used Adomian decomposition method and Haar wavelet method for solving some oscillatory problems. A comparison study has been done in this section to illustrate the accuracy and efficiency of both the methods. First of all, we are discussing different cases of oscillatory problems.

\section{(a) Damped Oscillations:}

Suppose a mass $m$ is suspended from the end $A$ of a light spring, the other end of which is fixed at $O$ (as in Fig. 1). Let $e(=\mathrm{AB})$ be the elongation produced by the mass $m$ hanging in equilibrium. If $k$ be the restoring force per unit stretch of the spring due to elasticity, then for the equilibrium at $B$, $\mathrm{mg}=\mathrm{T}_{1}=\mathrm{ke}$ 


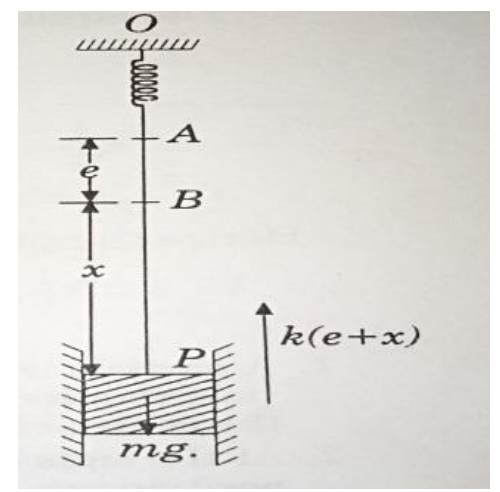

Fig. 1. Damped Forced Oscillation.

where $T_{1}$ is the tension in the elastic string. If the motion of the mass $\mathrm{m}$ be subject to additional force of resistance, the oscillation are said to be damped. The damping force may be constant or proportional to velocity. The latter type of damping is important and is usually called viscous damping. Now if the damping force be proportional to velocity $\left(=r \frac{d x}{d t}\right)$, then the equation of motion becomes

$\mathrm{m} \frac{\mathrm{d}^{2} \mathrm{x}}{\mathrm{dt}^{2}}=\mathrm{mg}-\mathrm{k}(\mathrm{e}+\mathrm{x})-\mathrm{r} \frac{\mathrm{dx}}{\mathrm{dt}}$

$=-\mathrm{kx}-\mathrm{r} \frac{\mathrm{dx}}{\mathrm{dt}}$

Letting $r / m=2 \lambda$ and $k / m=\mu^{2}$, it becomes

$\frac{\mathrm{d}^{2} \mathrm{x}}{\mathrm{dt}^{2}}+2 \lambda \frac{\mathrm{dx}}{\mathrm{dt}}+\mu^{2} \mathrm{x}=0$

Therefore, its auxiliary equation is

$D^{2}+2 \lambda D+\mu^{2}=0$

This implies $D=-\lambda \pm \sqrt{\lambda^{2}-\mu^{2}}$

To examine the physical significance of the solution of the above equation, three cases that arises:

Case I. When $\lambda>\mu$, the roots of the auxiliary equation are real and distinct say $\left(\gamma_{1}, \gamma_{2}\right)$.

Therefore, the solution of (16) is of the form

$x=c_{1} e^{\gamma_{1} t}+c_{2} e^{\gamma_{2} t}$

To determine constants, $c_{1}, c_{2}$, let the spring be stretched to a length $x=l$ and then

released so that

$x=l$ and $d x / d t=0$ at $t=0$.

From (17),

$l=c_{1}+c_{2}$

Also,

$\frac{d x}{d t}=c_{1} \gamma_{1} e^{\gamma_{1} t}+c_{2} \gamma_{2} e^{\gamma_{2} t}$

After using the conditions, we obtain

$\mathrm{c}_{1} \gamma_{1}+\mathrm{c}_{2} \gamma_{2}=0$

From (18) and (19), we obtain 
$c_{1}=\frac{-l \gamma_{2}}{\gamma_{1}-\gamma_{2}}, \quad c_{2}=\frac{l \gamma_{1}}{\gamma_{1}-\gamma_{2}}$

Therefore, the solution of (16) is

$\mathrm{x}=\frac{\mathrm{l}}{\gamma_{1}-\gamma_{2}}\left(\gamma_{1} \mathrm{e}^{\gamma_{2} \mathrm{t}}-\gamma_{2} \mathrm{e}^{\gamma_{1} \mathrm{t}}\right)$

which show that $x$ is always positive and decreases to zero as $t \rightarrow \infty$. The restoring force in this case, is so great that the motion is non-oscillatory and is therefore, referred to as over-damped or dead-beat motion.

Numerically, when $\lambda=2, \mu=\sqrt{3}$, from (16), we obtain

$x^{\prime \prime}+4 x^{\prime}+3 x=0$

with initial conditions $x(0)=2, x^{\prime}(0)=0$. The exact solution is

$x(t)=3 e^{-t}-e^{-3 t}$

\section{Adomian Decomposition Method:}

We define a linear operator $L=\frac{d^{2}}{d t^{2}}$ and inverse operator $L^{-1}=\iint_{0}^{t}() d t d$.$t . We obtain$

$\mathrm{x}_{0}=2, \quad \mathrm{x}_{1}=-3 \mathrm{t}^{2} \quad \mathrm{x}_{2}=-4 \mathrm{t}^{3}+\frac{3}{4} \mathrm{t}^{4}, \quad \mathrm{x}_{3}=-4 \mathrm{t}^{4}-\frac{6}{5} \mathrm{t}^{5}-\frac{3}{40} \mathrm{t}^{6}$,

$\mathrm{x}_{4}=\frac{16}{5} \mathrm{t}^{5}+\frac{6}{5} \mathrm{t}^{6}+\frac{9}{70} \mathrm{t}^{7}+\frac{9}{2240} \mathrm{t}^{8}+\cdots \cdots$

Therefore,

$\mathrm{x}(\mathrm{t})=\mathrm{x}_{0}+\mathrm{x}_{1}+\mathrm{x}_{2}+\mathrm{x}_{3}+\mathrm{x}_{4}+\cdots$

$x(t)=2-3 t^{2}+4 t^{3}-\frac{13}{4} t^{4}+2 t^{5}-\cdots$

\section{Haar Wavelet Method:}

Consider the approximation

$\mathrm{x}^{\prime \prime}(\mathrm{t})=\sum_{\mathrm{i}=1}^{\mathrm{n}} \mathrm{a}_{\mathrm{i}} \mathrm{h}_{\mathrm{i}}(\mathrm{t})$

Integrating with respect to $t$, we obtain

$x^{\prime}(t)=x^{\prime}(0)+\sum_{i=1}^{n} a_{i} P_{1, i}(t)$

Again, integrating with respect to $t$, we obtain

$\mathrm{x}(\mathrm{t})=\mathrm{x}(0)+\mathrm{x}^{\prime}(0) \mathrm{t}+\sum_{\mathrm{i}=1}^{\mathrm{n}} \mathrm{a}_{\mathrm{i}} \mathrm{P}_{2, \mathrm{i}}(\mathrm{t})$

From (20), we obtain

$\sum_{\mathrm{i}=1}^{\mathrm{n}} \mathrm{a}_{\mathrm{i}}\left[\mathrm{h}_{\mathrm{i}}(\mathrm{t})+4 \mathrm{P}_{1, \mathrm{i}}(\mathrm{t})+3 \mathrm{P}_{2, \mathrm{i}}(\mathrm{t})\right]=-4 \mathrm{x}^{\prime}(0)-3 \mathrm{x}(0)-3 \mathrm{tx}^{\prime}(0)$

From here, wavelet coefficients are obtained. The numerical solution is obtained by substituting the value of wavelet coefficients into (21).

Fig. 2 shows the absolute errors for Example 1 using Haar wavelet method. Fig. 3 shows the comparison of exact and Haar wavelet solutions for Example 1 for $J=3$. 


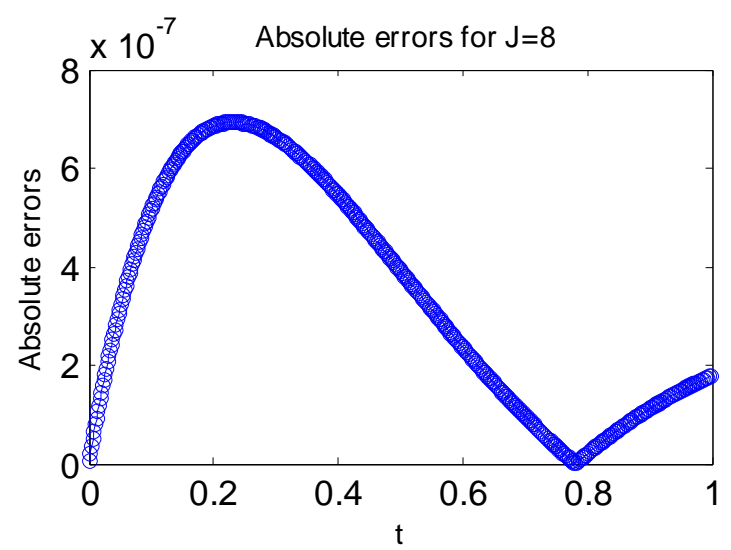

Fig. 2. Absolute errors for Example 1 using Haar wavelet method.

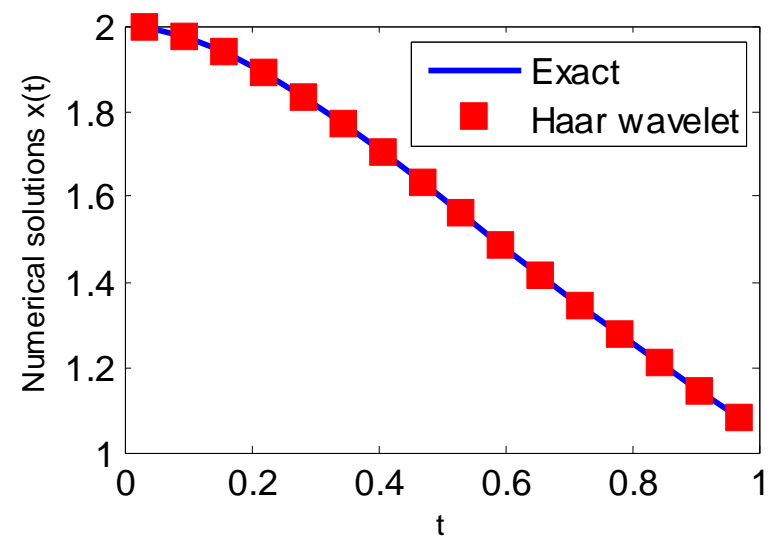

Fig. 3. Comparison of exact and Haar wavelet solutions for Example 1.

Case II. When $\lambda=\mu$, the roots of auxiliary equation are real and equal, (each being= $-\lambda)$.

The general solution of (16) is

$\mathrm{x}=\left(\mathrm{c}_{1}+\mathrm{c}_{2} \mathrm{t}\right) \mathrm{e}^{-\lambda \mathrm{t}}$

when $x=l$ and $d x / d t=0$ at $t=0$, we obtain

$\mathrm{c}_{1}=\mathrm{l}, \mathrm{c}_{2}=\lambda \mathrm{l}$

Therefore, the solution of (16) is

$\mathrm{x}=\mathrm{l}(1+\lambda \mathrm{t}) \mathrm{e}^{-\lambda \mathrm{t}}$

which shows that $x$ is positive and decreases to zero as $t \rightarrow \infty$. The nature of motion is similar to that of case I and is called the critically damped motion.

Numerically, letting $\lambda=\mu=1$. Consider the second order LDE

$\mathrm{x}^{\prime \prime}+2 \mathrm{x}^{\prime}+\mathrm{x}=0$

with initial conditions $x(0)=2, x^{\prime}(0)=0$. The exact solution is

$\mathrm{x}(\mathrm{t})=2(1+\mathrm{t}) \mathrm{e}^{-\mathrm{t}}$ 


\section{Adomian Decomposition Method:}

We define linear operator $L=\frac{d^{2}}{d x^{2}}$ and inverse operator is $L^{-1}=\iint_{0}^{t}() d t d$.$t . We obtain$

$\mathrm{x}_{0}=\mathrm{t}, \quad \mathrm{x}_{1}=-\mathrm{t}^{2}-\frac{\mathrm{t}^{3}}{6}, \quad \mathrm{x}_{2}=\frac{2}{3} \mathrm{t}^{3}+\frac{\mathrm{t}^{4}}{6}+\frac{\mathrm{t}^{5}}{120}, \mathrm{x}_{3}=-\frac{\mathrm{t}^{4}}{3}-\frac{\mathrm{t}^{5}}{10}-\frac{\mathrm{t}^{6}}{120}-\frac{\mathrm{t}^{7}}{5040}$

$x_{4}=\frac{2}{15} t^{5}+\frac{2}{45} t^{6}+\frac{t^{7}}{210}+\frac{t^{9}}{362800}, \ldots \ldots \ldots \ldots \ldots$

Therefore,

$\mathrm{x}(\mathrm{t})=\mathrm{x}_{0}+\mathrm{x}_{1}+\mathrm{x}_{2}+\mathrm{x}_{3}+\cdots$

$x(t)=t-t^{2}+\frac{t^{3}}{2}-\frac{t^{4}}{6}+\frac{t^{5}}{24}-\frac{t^{6}}{120}+\cdots$

Haar Wavelet Method: From (22), we obtain

$\sum_{i=1}^{n} a_{i}\left[h_{i}(t)+2 P_{1, i}(t)+P_{2, i}(t)\right]=-2 x^{\prime}(0)-x(0)-x^{\prime}(0) \cdot t$

From here, wavelet coefficients are obtained. The numerical solution is obtained by substituting the wavelet coefficients into (21).

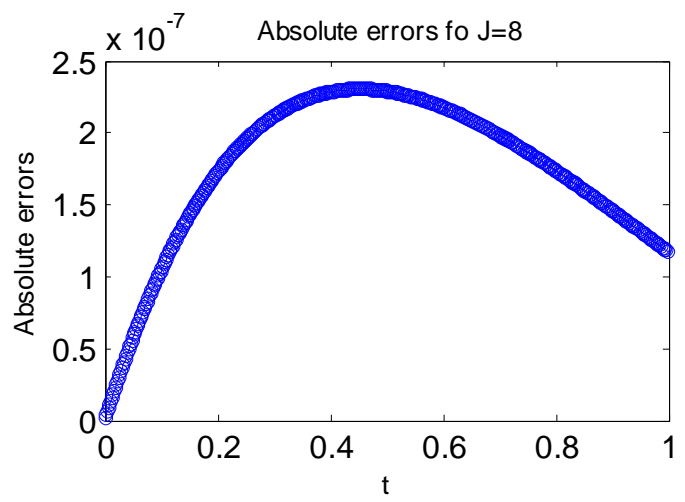

Fig. 4. Absolute errors for Example 2 using Haar wavelet method.

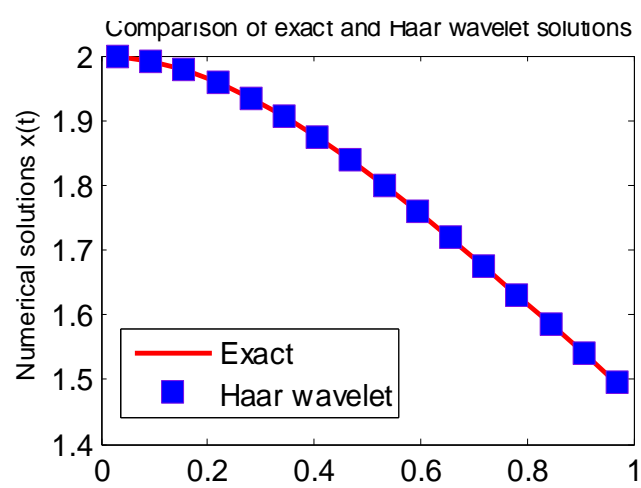

Fig. 5. Comparison of exact and Haar wavelet solutions for Example 2. 
Fig. 4 shows the absolute errors for Example 2 using Haar wavelet method. Fig. 5 shows the comparison of exact and Haar wavelet solutions for Example 2 for $J=3$.

Case III. When $\lambda<\mu$, the roots of the auxiliary equation are imaginary, that is $D=-\lambda \pm$ $i \alpha$, where $\alpha^{2}=\mu^{2}-\lambda^{2}$

Therefore the solution of (16) is

$\mathrm{x}=\mathrm{e}^{-\lambda \mathrm{t}}\left(\mathrm{c}_{1} \cos \alpha \mathrm{t}+\mathrm{c}_{2} \sin \alpha \mathrm{t}\right)$

when $x=l$ and $d x / d t=0$ at $t=0$, we obtain

$\mathrm{c}_{1}=\mathrm{l}, \mathrm{c}_{2}=\lambda \mathrm{l} / \alpha$

Thus the solution of (16) is

$\mathrm{x}=\mathrm{le}^{-\lambda t}\left(\cos \alpha \mathrm{t}+\frac{\lambda}{\alpha} \sin \alpha \mathrm{t}\right)$.

Numerically, letting $\lambda=\frac{1}{2}, \mu=1$. Consider the oscillatory equation

$\mathrm{x}^{\prime \prime}+\mathrm{x}^{\prime}+\mathrm{x}=0$

with initial conditions, $x(0)=2, x^{\prime}(0)=0$. The exact solution is

$\mathrm{x}(\mathrm{t})=2 \cdot \mathrm{e}^{-\mathrm{t} / 2}\left(\cos \frac{\sqrt{3}}{2} \mathrm{t}+\frac{1}{\sqrt{3}} \sin \frac{\sqrt{3}}{2} \mathrm{t}\right)$

\section{Adomian Decomposition Method:}

We define a linear operator $L=\frac{d^{2}}{d t^{2}}$ and inverse operator $L^{-1}=\iint_{0}^{t}() d t d$.$t . We obtain$

$x_{0}=2, \quad x_{1}=-t^{2} \quad x_{2}=\frac{t^{3}}{3}+\frac{t^{4}}{12}, \quad x_{3}=-\frac{t^{4}}{12}-\frac{t^{5}}{30}-\frac{t^{6}}{360}$,

$x_{4}=\frac{t^{5}}{60}+\frac{t^{6}}{120}+\frac{t^{7}}{840}+\frac{t^{8}}{20160},+\cdots$

Therefore,

$x(t)=2-t^{2}+\frac{t^{3}}{3}-\frac{t^{5}}{60}+\frac{t^{6}}{180}-\cdots$

\section{Haar Wavelet Method:}

From (23), we obtain

$\sum_{i=1}^{n} a_{i}\left[h_{i}(t)+P_{1, i}(t)+P_{2, i}(t)\right]=-x(0)-x^{\prime}(0)-x^{\prime}(0) \cdot t$

From here, wavelet coefficients are obtained. The numerical solution is obtained by substituting the wavelet coefficients into (21). 


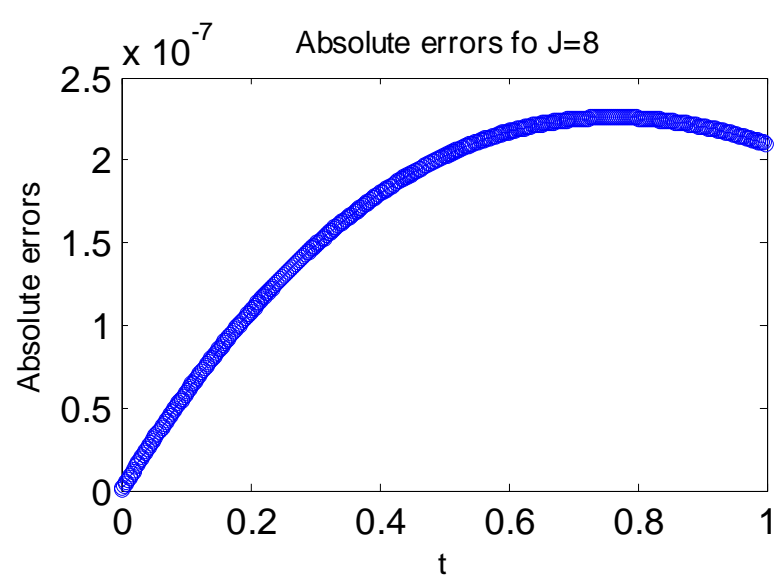

Fig. 6. Absolute errors for Example 3 using Haar wavelet method.

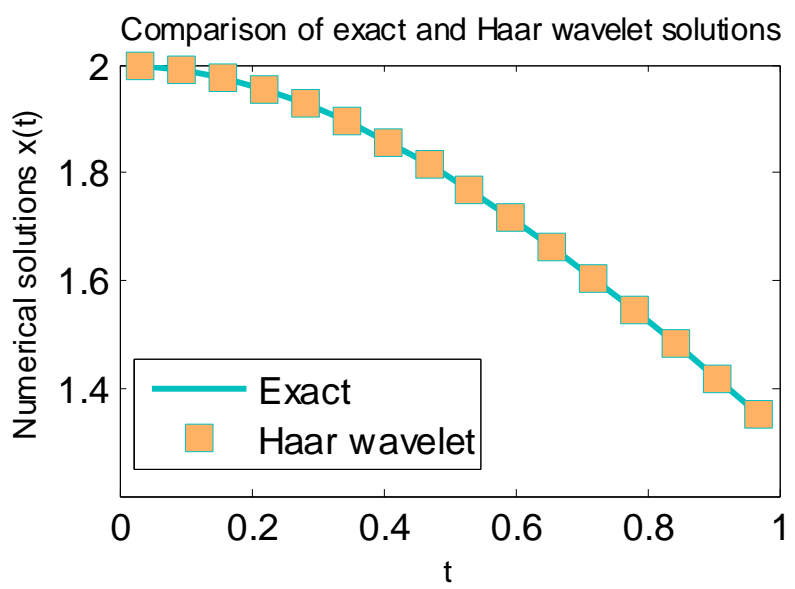

Fig. 7. Comparison of exact and Haar wavelet solutions for Example 3.

Fig. 6 shows the absolute errors for Example 3 using Haar wavelet method. Fig. 7 shows the comparison of exact and Haar wavelet solutions for Example 3 for $J=3$.

b) Free Oscillations: Suppose a mass $m$ is suspended from the end $A$ of a light spring, the other end of which is fixed at $O$ (as in Fig. 1). Let $e(=A B)$ be the elongation produced by the mass $m$ hanging in equilibrium. If $k$ be the restoring force per unit stretch of the spring due to elasticity, then for the equilibrium at $B$, $\mathrm{mg}=\mathrm{T}_{1}=\mathrm{ke}$

At any time $t$, after the motion ensues, let the mass be at $P$, where $B P=x$. Then the equation of motion of $m$ is

$\mathrm{m} \frac{\mathrm{d}^{2} \mathrm{x}}{\mathrm{dt}^{2}}=\mathrm{mg}-\mathrm{k}(\mathrm{e}+\mathrm{x})=-\mathrm{kx}$

On writing $k / m=\mu^{2}$, it becomes 
$\frac{\mathrm{d}^{2} \mathrm{x}}{\mathrm{dt}^{2}}+\mu^{2} \mathrm{x}=0$

This equation represents the free vibrations of the spring which are of the simple harmonic form having center of oscillation at $B$ its equilibrium position and the period of oscillation is

$\mathrm{T}=\frac{2 \pi}{\mu}=2 \pi \sqrt{\left(\frac{\mathrm{e}}{\mathrm{g}}\right)}$,

where $\frac{1}{\mu}=\sqrt{\left(\frac{\mathrm{m}}{\mathrm{k}}\right)}=\sqrt{\left(\frac{\mathrm{e}}{\mathrm{g}}\right)}$.

Numerically, letting $\mu=1$. Consider the oscillatory equation

$x^{\prime \prime}+x=0$

with initial conditions, $x(0)=0, x^{\prime}(0)=3$. The exact solution is $x(t)=3$ sint .

\section{Adomian Decomposition Method:}

We define an operator of $L=\frac{d^{2}}{d x^{2}}$ and inverse operator $L^{-1}=\iint_{0}^{t}() d t d$.$t . We obtain$

$\mathrm{x}_{0}=3 \mathrm{t}, \mathrm{x}_{1}=-\frac{\mathrm{t}^{3}}{2}, \mathrm{x}_{2}=\frac{\mathrm{t}^{5}}{40}, \mathrm{x}_{3}=-\frac{\mathrm{t}^{7}}{1680}, \mathrm{x}_{4}=\frac{\mathrm{t}^{9}}{120960}, \ldots \ldots \ldots$

Therefore,

$\mathrm{x}(\mathrm{t})=\mathrm{x}_{0}+\mathrm{x}_{1}+\mathrm{x}_{2}+\mathrm{x}_{3}+\mathrm{x}_{4}+\mathrm{x}_{5}+\cdots$

$x(t)=3 t-\frac{t^{3}}{2}+\frac{t^{5}}{40}-\frac{t^{7}}{1680}+\frac{t^{9}}{120960}-\frac{t^{11}}{13305600}+\cdots \cdots \cdots$

Haar wavelet method: From (23), we obtain

$\sum_{i=1}^{n} a_{i}\left[h_{i}(t)+P_{2, i}(t)\right]=-x(0)-x^{\prime}(0) \cdot t$

From here, wavelet coefficients are obtained. The numerical solution is obtained by substituting the wavelet coefficients into (21).

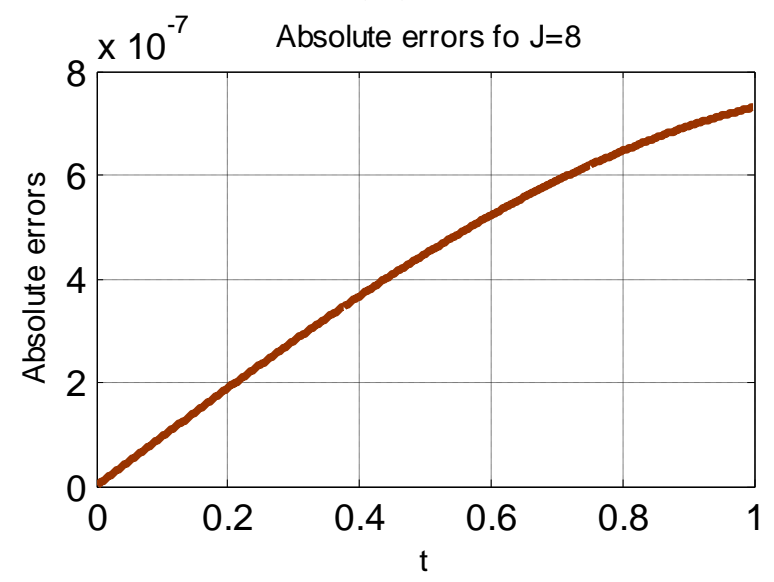

Fig. 8. Absolute errors for Example 4 using Haar wavelet method. 


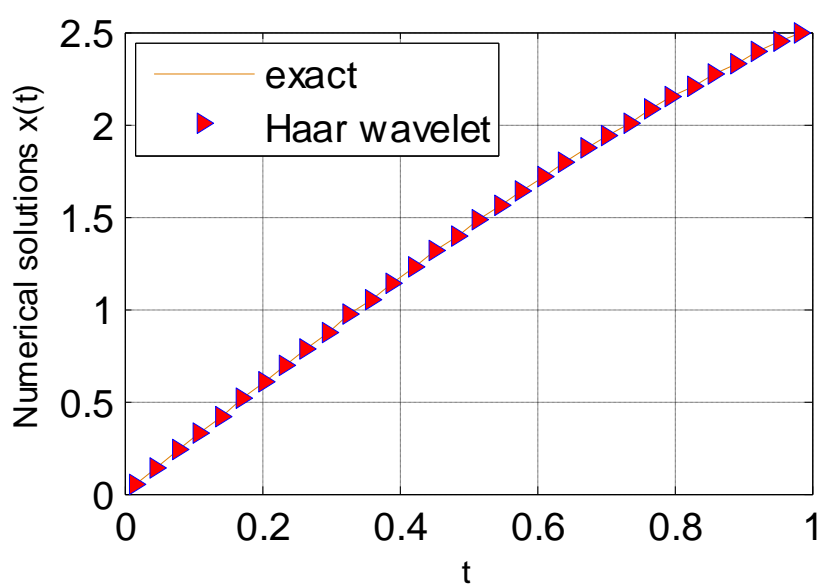

Fig. 9. Comparison of exact and Haar wavelet solutions for Example 4.

Fig. 8 shows the absolute errors for Example 4 using Haar wavelet method. Fig. 9 shows the comparison of exact and Haar wavelet solutions for Example 4 for $J=3$.

\section{Conclusion}

The goal to obtain the numerical solutions for oscillatory problems using Adomian decomposition method and Haar wavelet method has been achieved. Adomian decomposition method plays a significant role for solving such type of problems and give solutions in term of infinite series. On the other hand, the theoretical elegance of the Haar wavelet approach can be appreciated from the simple mathematical relations and their compact derivations and proofs. It has been well demonstrated that while applying the nice properties of Haar wavelets, the ordinary differential equations arising in oscillatory problems can be solved conveniently and accurately by using Haar wavelet method systematically. In the present paper only linear equations are considered, but these methods are also applicable for nonlinear systems. An authentic conclusion can be drawn from the numerical results that the Haar wavelet method provides more accurate numerical solutions than Adomian decomposition method. In our opinion the Haar wavelet method is wholly competitive in comparison with the classical methods. Future work will involve the extension of the scheme to two and three dimensional problems.

\section{References}

1. K. Hussain, F. Ismail, and N. Senu, Int. J. Pure Appl. Math. 106, 715 (2016). http://doi:10.12732/ijpam.v106i3.2

2. S. Z. Ahmad, F. Ismail, and N. Senu, J. Math. 2018, 7 (2018). https://doi.org/10.1155/2018/2960237

3. J. M. Franco, Appl. Numer. Math. 50, 427 (2004).

4. M. Fayz-Al-Asad, M. M. A. Sarker, and M. J. H. Munshi, J. Sci. Res. 11, 173 (2019). http://dx.doi.org/10.3329/jsr.v11i2.38797 
5. M. J. H. Munshi, M. A. Alim, M. Ali, and M. S. Alam, J. Sci. Res. 9, 145 (2017). http://dx.doi.org/10.3329/jsr.v9i2.29644

6. G. Adomian, J. Math. Anal. Appl. 135, 501 (1988).

7. S. Somali and G. Gokmen, Surveys Math. Its Applicat. 2, 11 (2007),

8. Y. Cherruault, Kybernetes 18, 31(1989).

9. I. Mustafa, Appl. Math. Comput. 170, 76 (2005).

10. C. F. Chen and C. H. Hsiao, IEEE Proc. Pt. D. 144, 87 (1997).

11. G. Hariharan and K. Kannan, World Appl. Sci. J. 23, 1 (2013).

12. G. Hariharan and K. Kannan, Appl. Math. Model. 38, 799 (2014).

13. S. C. Shiralashetti and R. A. Mundewadi, Bull. Math. Sci. Applicat. 18, 50 (2017). https://doi.org/10.18052/www.scipress.com/BMSA.18.50

14. U. Saeed and M. Rehman, Int. J. Math. Math. Sci. 2014, 1 (2014). http://dx.doi.org/10.1155/2014/174819

15. G. Hariharan, K. Kannan, J. Math. Chem. 48, 1044 (2010). https://doi:10.1007/s10910-0109724-0

16. A. Mohammadi, N. Aghazadeh, and S. Rezapour, Math. Sci. 13, 255 (2019). https://doi.org/10.1007/s40096-019-00295-8

17. I. Singh, S. Arora, and S. Kumar, Int. J. Pure Appl. Math. 104, 495 (2015). http://dx.doi.org/10.12732/ijpam.v104i4.1

18. I. Singh and S. Kumar, Math. Sci. 11, 145 (2017). https://doi.org/10.1007/s40096-017-0220-6

19. J. Biazar and S. M. Shafiof, Int. J. Contemp. Math. Sci. 2, 975 (2007).

20. J. Biazar and M. Pourabd, Int. Math. Fourm 1, 1919 (2006). 